\title{
HPV Infection and Cervical Abnormalities in HIV Positive Women in Different Regions of Brazil, a Middle-Income Country
}

\author{
Beatriz C Freitas ${ }^{\star}$, Tamy T Suehiro ${ }^{\star}$, Marcia EL Consolaro, Vania RS Silva*
}

\begin{abstract}
Human papillomavirus is a virus that is distributed worldwide, and persistent infection with high-risk genotypes (HR-HPV) is considered the most important factor for the development of squamous cell cervical carcinoma (SCC). However, by itself, it is not sufficient, and other factors may contribute to the onset and progression of lesions. For example, infection with other sexually transmitted diseases such as human immunodeficiency virus (HIV) may be a factor. Previous studies have shown the relationship between HPV infection and SCC development among HIV-infected women in many regions of the world, with great emphasis on low- and middleincome countries (LMICs). Brazil is considered a LMIC and has great disparities across different regions. The purpose of this review was to highlight the current knowledge about HPV infection and cervical abnormalities in HIV+ women in Brazil because this country is an ideal setting to evaluate HIV impact on SCC development and serves as model of LMICs and low-resource settings.
\end{abstract}

Keywords: Human papillomavirus - human immunodeficiency virus - cervical abnormalities - epidemiology - Brazil

Asian Pac J Cancer Prev, 16 (18), 8085-8091

\section{Introduction}

The association between persistent infection by highrisk human papillomavirus (HR-HPV), squamous cell cervical carcinoma (SCC) and some vaginal and anal cancers has been well-established (Stier, 2009; Spangler and Minger, 2010; IARC, 2011). In addition, recent data demonstrate that HR-HPV is also associated with a subset of head and neck cancers, including $50-75 \%$ of oropharyngeal cancers (Marur et al., 2010; Beachler et al., 2014). HPV infection is particularly burdensome for human immunodeficiency virus (HIV+)-infected women, as they are more susceptible to infection and less likely to clear the virus, which in turn increases their risk of developing all types of HPV-associated cancers compared to the general population. Moreover, in HIV+ women, SCC tends to respond poorly to recommended therapies, has a proclivity to be more aggressive, and may have an overall worse prognosis (Luque et al., 2010).

Although the incidence of total cancers has diminished in HIV+ individuals with the advent of highly active antiretroviral therapy (HAART), it has not diminished for certain HPV-related cancers (Adler, 2010; Piketty et al., 2012). With the increase in the survival of HIV+ women due to HAART, there is an increased opportunity for the progression of oncogenic viral infections into malignancies, particularly in HPV-associated oral, genital, and anal cancers (Adler, 2010; Piketty et al., 2012; Ortiz et al., 2014). Currently, the HIV/AIDS pandemic is predominantly impacting the poorest and the youngest in resource-limited settings. Women are over represented in these groups, which raises concerns about the development of HPV-related cancers in HIV+ women, particularly in low- and middle-income countries (LMICs) such as Brazil. With the recent approval of the 9-valent HPV vaccine, there is real promise to dramatically decrease the risk of persistent HR-HPV infections and HPV-related pre-cancers and malignancies. At appropriate vaccination thresholds, this vaccine may have a tremendous impact on screening as well, with a legitimate rationale for increasing screening intervals given the anticipated decrease in the disease burden. Furthermore, understanding the specific prevalence and distribution of HPV genotypes in different geographic locations will help yield further insight into whether this new vaccine holds any promise and value (Joura et al., 2015).

Brazil has a large and heterogeneous territory, divided into North, Northeast, Central-West, Southeast and Southern regions (Figure 1), with internal inequalities and stark differences in demographic, economic, social, cultural and health conditions. In this scenario, the Southeast and Southern regions have a higher gross domestic product, while the North and Northeast regions are the poorest (Paim et al., 2011).

The purpose of this review was to highlight the current knowledge about HPV infection and cervical 


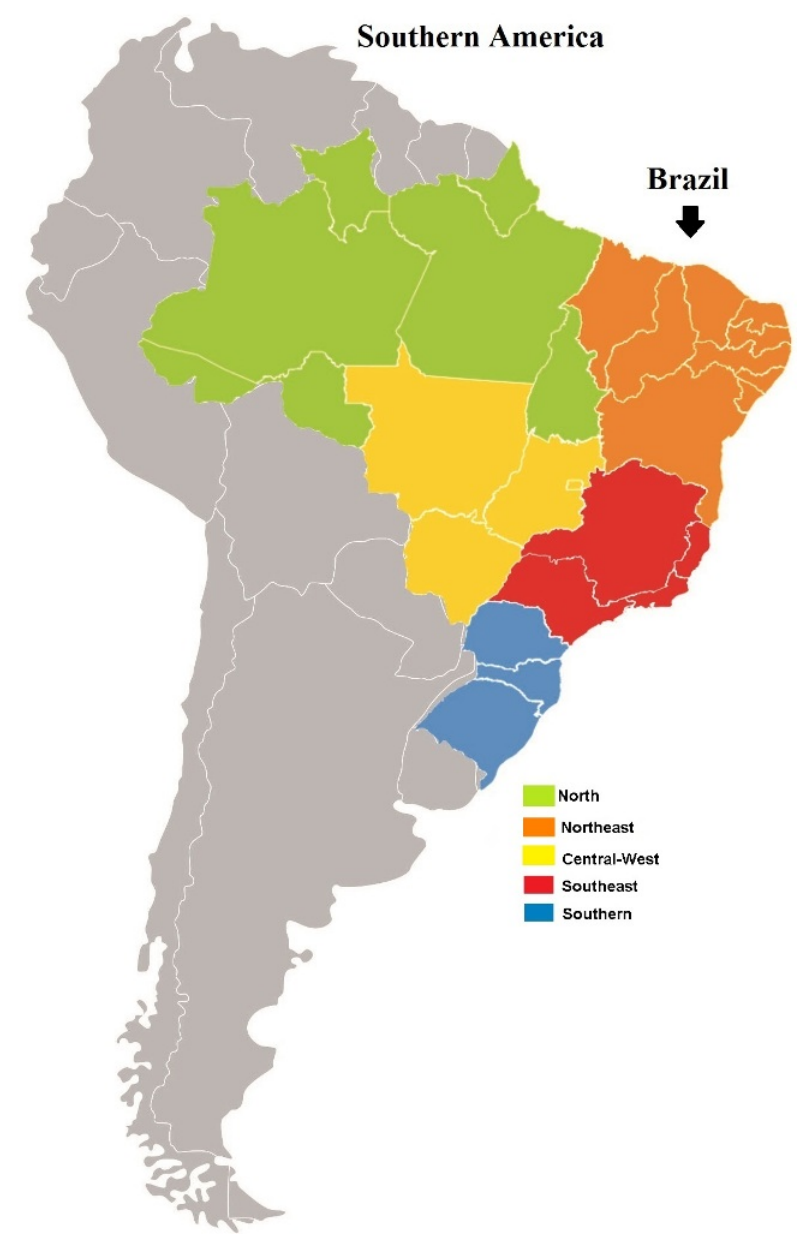

Figure 1. Different Regions of Brazil

abnormalities in HIV+ women in Brazil. This review is significant because although Brazil is considered a LMIC and it is on the cusp of becoming a high-income country, it is a country with great socioeconomic disparities. Furthermore, Brazil accounts for $47 \%$ of new HIV cases in Latin America (Portal Brasil, 2015). Therefore, Brazil is the ideal setting to evaluate the impact of HIV on SCC development and serves as model of LMICs and lowresource settings.

\section{Review Criteria}

PubMed, MEDLINE, Google Scholar and Lilacs were searched for full-text papers and abstracts published in the English or Portuguese languages between 2010 and 2014. The search was completed in December 2014. The following MeSH terms were used: "papillomavirus infections", "papillomaviridae", "HIV infections", "Brazil", "pregnancy", "biological markers", "HIV" and "HPV". The reference lists of the selected papers were also searched for additional relevant publications.

\section{HIV Burden among Brazilian Women}

The HIV virus belongs to the Lentivirus genus of the Retroviridae family and can be subdivided into HIV-1 and HIV-2. The infection involves multiple stages, and when the efficacy of treatment becomes limited, the immune system is weakened, favoring the emergence of opportunistic infections, neoplasms, autoimmune and metabolic disorders. The transmission occurs through sexual contact, vertical contact, blood and blood derivatives. As the infection progresses, the $\mathrm{CD} 4+\mathrm{T}$ cell lymphocyte (CD4+) count decreases, and the viral load tends to increase. In Brazil, the decisive criterion for AIDS occurs at a CD4+ count below 350 cells $/ \mathrm{mm}^{3}$ (Requejo, 2006).

It is estimated that 1.6 million individuals are HIV+ in Latin America, and $75 \%$ of these cases are concentrated in five countries (Brazil, Mexico, Colombia, Argentina, and Venezuela). While there has been an overall decrease of $3 \%$ in new infections in the region between 2005 and 2013, there has been an increase of $11 \%$ in new cases in this same time period in Brazil compared to a decrease of 39\% in Mexico. In 2013, Brazil accounted for 47\% of new HIV cases in Latin America (Portal Brasil, 2015).

In 2014, approximately 734,000 Brazilian individuals were HIV+ (0.4\% prevalence). The prevalence of HIV+ cases was higher among individuals between the ages of 15 and $49(0.6 \%)$, and men $(0.7 \%)$ compared to $0.4 \%$ among women. Between 1980 and 2014, 54\% of HIV+ men and $50.3 \%$ of HIV+ women were between the ages of 25 and 39 years. The rate of HIV infection is increasing progressively in women compared to men, highlighting the feminization of the epidemic process. Of the 592,914 diagnoses from 1980 to June 2010, 385,818 were for males and 207,080 were for females, with a similar pattern between groups (Felix and Ceolim, 2012). The increasing HIV-positive cases in the female population are associated with socio-economic factors and unprotected sexual intercourse. In this group, it was noticed that the association between other sexually transmitted diseases (STD), and generally the reason that women seek medical assistance, is related to the appearance of gynecological infections such as syphilis, candidiasis, herpes simplex, among others (Santos et al., 2009).

Differences in incidence around Brazilian territory were also observed, where the increase in infection and the AIDS mortality rate are evident in the North and Northeast regions, but are declining in the Southeast (Teixeira et al., 2012). However, most of the HIV+ cases were concentrated in the Southeast and Southern regions of Brazil, which corresponds to $54.4 \%$ and $20 \%$ of the total cases between 1980 and 2014, respectively. There is also a peculiar pattern of disease with regards to gender and geographical region. For instance, the Southern region is the only geographical region where HIV incidence is higher among women compared to men (1.5 times higher). HIV incidence across age also shows a gender difference in all regions of the country. That is, as age increases, the age/gender ratio decreases, revealing a greater number of males in the younger age group and higher representation of women in older age groups (Boletim Epidemiologico, 2014).

The Brazilian government implemented the use of HAART in 1996, leading to a substantial reduction in AIDS-related mortality (13\% decrease in the past 10 years). According to data from the Ministry of Health, $68 \%$ of the diagnosed HIV+ cases receive their care through the public health system (INCA, 2014). 


\section{SCC Burden among Brazilian Women}

HPV belongs to the Papillomaviridae family, and more than 200 different HPV genotypes have been isolated and sequenced, with approximately 40 of these being known to infect the genital tract and approximately 18 genotypes being classified as HR-HPV (de Sanjose et al., 2010; Smith-McCune et al., 2010). HPV infection is an important STD and is considered the most prevalent in the world and the main factor in the genesis of SCC (Shrestha et al., 2010; Smith-McCune et al., 2010). HPVDNA is present in $99.7 \%$ of all SCC (Sudenga et al., 2014); HPV-16 and HPV-18 are the genotypes most frequently associated with this type of cancer (McKenzie et al., 2010; Firnhaber et al., 2011). The majority of HPV infected patients are able to clear the infection naturally, and only a small proportion will progress to SCC (Sudenga et al., 2014). The most important protective immune mechanism is the suppression or elimination of the HPV virus and the immune response mediated by cells within 1-2 years of exposure (Rosa et al., 2008). A persistent infection of the HR-HPV genotypes is considered the most important factor for the development of cervical lesions and progression to SCC; however, it is not a sufficient cause (Sudenga et al., 2014). There are other factors that can contribute to the emergence and progression of the lesion, for example, high viral load, number of pregnancies, use of oral contraceptives, smoking, immunosuppression, other STD infections and genetic predisposition (Rosa et al., 2008).

Despite these advancements, SCC is the fourth most common cancer among women worldwide (IARC, 2012; Koh et al., 2015). Its incidence varies between different regions, and it is well established that it is higher in developing countries than in developed countries (Ferlay et al., 2010; Sudenga et al., 2014). The estimated unadjusted SCC incidence rate in 2014 was 15.3/100,000 women in Brazil; it is the third most prevalent non-melanoma cancer among women in Brazil, with differences around all territories. It is most prevalent in the North region, followed by Northeast and CentralWest, then the Southeast and finally the Southern region. The unadjusted SCC mortality in 2012 was 5.32/100,000 women with $54 \%$ of deaths occurring between the ages of 30 and 59 years. While SCC mortality has decreased in developed countries, it increased in Brazil between 2000 and 2012 (INCA, 2014).

\section{SCC and HIV}

Several studies have established that SCC risk is closely related to women's immune status and, since 1993, SCC has been classified as an AIDS-defining disease. HPV infection can be more easily investigated in HIV+ women because they are more vulnerable to infection and less susceptible to clear the virus, increasing the risk of developing cervical lesions and cancer later (Denny et al., 2012). HIV infection triggers a gradual loss of CD4+, which is associated with increased HPV infection and viral persistence. In addition, infection with multiple HPV genotypes is common (Vaz et al., 2011). Studies linking HIV/AIDS and cancer registries have reported a 2- to 22-fold increased risk of SCC among HIV+ women compared with the general female population in the same geographical area (Denny et al., 2012). The high prevalence of cervical lesions associated with HIV+ women highlighted that the immune response plays an important role in the development of SCC (Vaz et al., 2011). Still, SCC can be more aggressive and refractory to treatment, with high rates of recurrence, and the severity is directly related to the degree of immunosuppression. Furthermore, it presents a poorer prognosis compared to those not associated with HIV (Paulo et al., 2007).

In fact, some studies have consistently demonstrated that HIV+ women are more frequently infected with HPV genotypes that are not -16 and -18 , such as -52 and -58 (Blossom et al., 2007; McKenzie et al., 2010). Accordingly, knowledge about the HPV genotype distribution in HIV+ women in different world regions is critical, especially given the recent approval of the next generation 9-valent HPV vaccine recently approved by the United States Food and Drug Administration (FDA, December 2014). When compared to the quadrivalent HPV vaccine, the 9-valent vaccine prevented infection and disease specifically related to HPV $-31,-33,-45,-52$ and -58 , and generated an equivalent antibody response to HPV $-6,-11,-16$, and -18 . This vaccine also holds the potential of markedly decreasing the incidence of abnormal cervical cytology and associated diagnostic and therapeutic procedures (Joura et al., 2015). This vaccine has the very high potential of markedly reducing the incidence of HPV-related pre-cancers and cancers when given at appropriate vaccination thresholds, which can contribute greatly to controlling cervical cancer in HIV+ women.

\section{Molecular Prevalence of HPV and Genotypes in HIV+ Women According to the Region}

Molecular studies evaluating cervical infections by HPV and genotype distribution in Brazilian HIV+ women between 2010 and 2014 were performed only in the Southern and Southeast regions of the country (Table 1).

In the Southern region, Entiauspe et al. (2010) showed that the HPV prevalence was similar between HIV+ and HIV- women (76.3\% and $60.0 \%$, respectively). The most frequent genotype in both groups was HPV-16; however, an overall greater frequency of oncogenic genotypes was observed in HIV+ $(46.7 \%)$ compared with HIV- women (16.7\%). Instead, in 2011, a descriptive cross-sectional study by Fedrizzi et al. showed a higher prevalence of HPV in HIV+ women with or without HAART in comparison to HIV- women $(70.0 \%$ and $21.2 \%$, respectively), but the frequency of HR-HPV was similar (71.4\%) among the two groups. A study conducted by Rocha-Brischiliari et al. (2014) evaluated a population of HIV+ women who were using HAART. In addition to the high prevalence of HPV (46.6\%) detected, a high proportion of HPV coinfections was found (two or more genotypes in the same women) (23.0\%). Surprisingly, HPV-72 (LR-HPV) was the most frequent genotype detected, followed by HPV -16, -31 and -51 (HR-HPV). 
The largest number of studies have been conducted in the Southeast region. Correa et al. (2011) found the frequency of HPV in HIV+ women to be $78.8 \%$, with a similar frequency for HR- and LR-HPV genotypes. HPV-16 and - 6 were the most frequent genotypes, and a high prevalence of HPV co-infections were also detected (64.8\%). Melgaco et al. (2011) evaluated HIV+ women, the majority of whom were treated with HAART. The prevalence of HPV was $60.0 \%$, and HPV-16 was the most prevalent, followed by other HR-HPV genotypes such as HPV-53 and -58. The frequency of HPV co-infections was $20.0 \%$, all with at least one HR-HPV genotype being involved. Accordingly, Andrade et al. (2011) showed an HPV prevalence of $50.0 \%$ in HIV+ women. In 2011, Mattos et al. showed a similar prevalence of HPV in HIV+ and HIV- women (29.5\% and $25.6 \%$, respectively). In HIV+ women, 18 different HPV genotypes were detected, and in HIV-women, 19 different genotypes were detected. In both groups, HPV -16 was the most prevalent genotype and HPV co-infection showed similar frequencies.

In 2012, Teixeira et al., showed HPV infection in $69.2 \%$ of HIV+ women, of which, $44.5 \%$ had HR-HPV genotypes. In a retrospective cohort study, Araujo et al. (2012) showed HPV in $68.1 \%$ of HIV+ women, of which, $17.2 \%$ had HR-HPV, $12.9 \%$ had LR-HPV, and HR- and LR-HPV co-infections accounted for $23.6 \%$. In this study, HPV was not genotyped in $14,4 \%$ of women. Finally, Lima et al. (2014) obtained similar results for the prevalence of HPV (41.0\% and 45.0\%) and HR-HPV (87.9\% and 91.1\%) in HIV+ and HIV- women, respectively.

Together, these studies suggest that single HPV infections and HPV co-infections are very common in HIV+ women, with most involving HR-HPV genotypes. Overall, HPV-16 was the most prevalent genotype; however, some unusual genotypes were detected in some studies.

\section{Prevalence of Cervical Abnormalities in HIV+ Brazilian Women}

The Pap smear is the conventional method used for SCC and precursor lesion screening and is the method adopted by Brazil Government. The cytological findings are classified according to the Bethesda System: negative for intraepithelial lesion and malignancy (NILM), squamous intraepithelial lesions (SIL) of low (LSIL) or high (HSIL) grade and SCC. Atypical squamous cells (ASC) can be classified in ASC of undetermined significance (ASC-US) or impossible to exclude HSIL (ASC-H) (Solomon and Nayar, 2005). In Brazil, the Ministry of Health adopted the following protocol: women with persistent LSIL or ASC-US, or with an HSIL or ASC-H diagnosis, are forwarded to colposcopy followed by biopsy. In the histological evaluation, the abnormalities would be classified as cervical intraepithelial neoplasia (CIN) grades I, II or III, carcinoma in situ or SCC (INCA, 2011).

In Table 2 and Figure 2, possible observed studies related to abnormal cervical findings in HIV+ women are shown. In the Southern, Southeast and Northeast regions, some studies compared cytological findings of HIV+ and
HIV- women. In the Southern region, Entiauspe et al. (2010) showed a higher rate of cytological abnormalities in HIV+ $(61.3 \%)$ compared to HIV-women (8.4\%). With regards to the cytological findings, ASC-US (7.9\%), LSIL (27.1\%) and HSIL (26.3\%) were detected in HIV+ women, while in HIV- women, only ASC-US (4.2\%) and LSIL $(4.2 \%)$ were detected. Similar results were found in the Northeast, where in $25 \%$ of samples from HIV+ women cytological abnormalities were detected including LSIL (18.8\%) and HSIL (6.2\%). Although HIV- women also had LSIL and HSIL, the frequency was reduced $(6.6 \%$ and $1.3 \%$, respectively) (Oliveira et al., 2010). However, another study in the Southeast found no observed difference in the prevalence of abnormal cytological findings between HIV+ $(23.0 \%)$ and HIV- $(24.0 \%)$ women; HSIL was not found. The authors suggested that these similar prevalence rates may be because the HIVgroup had a higher risk for other STDs than HIV+ women (Lima et al., 2014).

Other studies in the Southern and Southeast regions evaluated only cytological findings of HIV+ women. A low prevalence of cervical abnormalities was found, and the most prevalent abnormal cytologies were ASC-US and/or LSIL (Melgaco et al., 2012; Teixeira et al., 2012; Rocha-Brischiliari et al., 2014).

Regarding histopathological findings, in the Southeast region, similar results were shown. Andrade et al. (2011), in a prospective open cohort study, observed the prevalence of CIN I $(20.0 \%)$, CIN II $(3.5 \%)$, CIN III (2.2\%) and just one woman with SCC between HIV+ women. In 2012, Teixeira and coworkers showed CIN that in $23.3 \%$ of HIV+ women evaluated, CIN I (17.3\%) and CIN II/III (6.0\%) were included. A retrospective and longitudinal cohort study showed that during follow-up, $13.5 \%$ of HIV+ women developed CIN and of them, $89.4 \%$ had CIN I, 6.4\% had CIN II and $4.2 \%$ had CIN III (Araujo et al., 2012). Therefore, low-grade abnormalities were the majority of findings and CIN I was the most prevalent in all studies. The results from only one study in

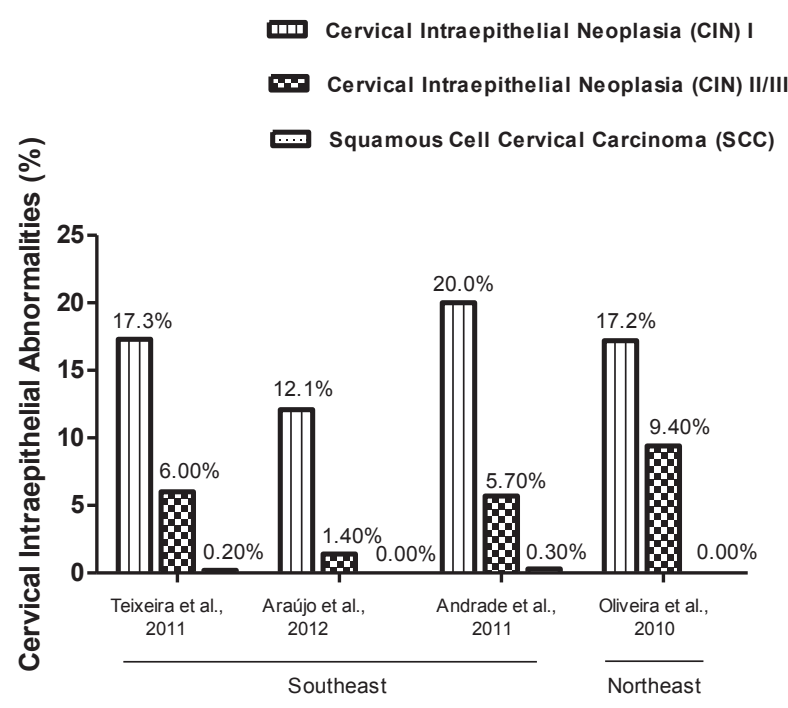

Figure 2. Cervical Intraepithelial Abnormalities in the Histopathological Diagnosis of HIV-Positive Brazilian Women 
HPV Infection and Cervical Abnormalities in HIV Positive Women in Different Regions of Brazil, a Middle-Income Country Table 1. Prevalence and Genotypes of HPV in HIV-positive or negative Brazilian women

\begin{tabular}{|c|c|c|c|c|c|c|c|c|}
\hline Region of Brazil & $\begin{array}{l}\text { Author } \\
\text { Year }\end{array}$ & HIV & $\mathrm{N}$ & $\begin{array}{c}\mathrm{HPV}+ \\
(\%)\end{array}$ & $\begin{array}{l}\text { LR-HPV } \\
(\%)\end{array}$ & $\begin{array}{l}\text { HR-HPV } \\
(\%)\end{array}$ & $\begin{array}{c}\text { Multiple genotypes } \\
(\%)\end{array}$ & $\begin{array}{l}\text { Most prevalent } \\
\text { genotypes }\end{array}$ \\
\hline \multicolumn{9}{|c|}{ Non-pregnant women } \\
\hline \multirow[t]{2}{*}{ Southern } & Entiauspe & + & 38 & 76.3 & -- & 46.7 & NR & 16.18 \\
\hline & et al., 2010 & - & 60 & 60.0 & -- & 16.7 & NR & \\
\hline \multirow[t]{2}{*}{ Southern } & Fedrizzi & + & 20 & 70.0 & 64.3 & 71.4 & 35.7 & NR \\
\hline & et al., 2011 & - & 99 & 21.2 & 52.4 & 71.4 & 23.8 & \\
\hline \multirow[t]{2}{*}{ Southern } & ocha-Brischiliari & + & 178 & 46.6 & 14.6 & 32.0 & 23.0 & $72,16,31,51$ \\
\hline & et al., 2014 & - & -- & -- & -- & -- & -- & -- \\
\hline \multirow[t]{2}{*}{ Southeast } & Andrade & + & 366 & 50.0 & NR & 47.0 & NR & NR \\
\hline & et al., 2011 & - & -- & -- & -- & -- & -- & -- \\
\hline \multirow[t]{2}{*}{ Southeast } & Côrrea & + & 288 & 78.8 & 71.4 & 70.5 & 64.8 & 6,16 \\
\hline & et al., 2011 & - & -- & -- & -- & -- & -- & -- \\
\hline \multirow[t]{2}{*}{ Southeast } & Mattos & + & 112 & 29.5 & NR & 54.5 & 21.2 & $16,6,11,53$ \\
\hline & et al., 2011 & - & 172 & 25.6 & NR & 59.0 & 13.6 & $16,6,53$ \\
\hline \multirow[t]{2}{*}{ Southeast } & Melgaço & + & 140 & 60.0 & 24.2 & 74.8 & 20.0 & $16,58,53$ \\
\hline & et al., 2011 & - & -- & -- & -- & -- & -- & -- \\
\hline \multirow{2}{*}{ Southeast } & Araújo & + & 348 & 68.1 & 12.9 & 17.2 & 23.6 & NR \\
\hline & et al., 2012 & - & -- & -- & -- & -- & -- & -- \\
\hline \multirow[t]{2}{*}{ Southeast } & Teixeira & + & 494 & 69.2 & 51.8 & 44.5 & NR & NR \\
\hline & et al., 2012 & - & -- & -- & -- & -- & -- & -- \\
\hline \multirow[t]{2}{*}{ Southeast } & Lima & + & 100 & 41.0 & 12.2 & 87.8 & NR & NR \\
\hline & et al., 2014 & - & 100 & 45.0 & 8.90 & 91.1 & NR & NR \\
\hline \multicolumn{9}{|c|}{ Pregnant women } \\
\hline \multirow[t]{2}{*}{ Southeast } & Jalil & + & 54 & 100 & NR & NR & NR & $, 11,18,16,31$ \\
\hline & et al., 2013 & - & 97 & 100 & NR & NR & NR & \\
\hline \multirow[t]{2}{*}{ Southeast } & Meyrelles & + & 140 & 84.3 & 20.2 & 79.8 & 16.3 & $16,58,35,53$ \\
\hline & et al., 2013 & - & -- & -- & -- & -- & -- & -- \\
\hline
\end{tabular}
papillomavirus; NR: not reported;--: not evaluated

Table 2. Cytological Findings of HIV-positive Non-pregnant Brazilian Women

\begin{tabular}{|c|c|c|c|c|c|c|}
\hline Region of Brazil & Author Year & HIV & $\operatorname{NILM}(\%)$ & ASC-US + LSIL (\%) & ASC-H + HSIL (\%) & $\operatorname{SCC}(\%)$ \\
\hline \multirow[t]{2}{*}{ Southern } & Teixeira et al., 2012 & & & & & \\
\hline & Entiauspe et al., 2010 & + & 44.8 & 35.0 & 26.3 & 0.00 \\
\hline \multicolumn{2}{|c|}{ Rocha-Brischiliari et al., 2014} & + & 92.7 & 6.76 & 0.56 & 0.00 \\
\hline $\begin{array}{l}\text { HIV: }+ \text { Rocha-Bris } \\
\text { NILM }(\%): 85.8\end{array}$ & Melgaço et al., 2011 & + & 57.1 & 35.0 & 7.90 & 0.00 \\
\hline ASC-US + LSIL: 12.4 & Araújo et al., 2012 & + & 92.2 & NR & NR & NR \\
\hline ASC-H + HSIL (\%): 1.60 & Lima et al., 2014 & + & 77.0 & 20.0 & 3.00 & 0.00 \\
\hline $\operatorname{SCC}(\%): 0.20$ & Oliveira et al., 2010 & + & 75.0 & 18.8 & 6.20 & 0.00 \\
\hline
\end{tabular}

HIV: human immunodeficiency virus; NILM: negative for intraepithelial lesion or malignancy; ASC-US: atypical squamous cells of undetermined significance; LSIL: low-grade squamous intraepithelial lesion; ASC-H: atypical squamous cells of undetermined significance not possible exclude HSIL; HSIL: high-grade squamous intraepithelial lesion; SCC: squamous cell cervical carcinoma; NR: not reported

the Northeast region were similar to the Southeast region, with a low prevalence of CIN. However, in this study, the frequency of CIN was higher in HIV+ $(26.6 \%)$ women compared to HIV- women (6.6\%), specifically those that did not use HAART, although this difference was not statistically significant (Oliveira et al., 2010).

Overall, studies showed that the prevalence of HPV infection in HIV+ women is high, while that of CIN is low. It is possible that these findings are due to the great majority of studies being performed in the Southern and Southeast of Brazil, as these regions are the most developed compared to others. In these regions, HIV+ women are has better follow-up statistics and correctly use the HAART, which seems to protect against the development of cervical lesions (Rocha-Brischiliari et al., 2014). The prevalence of low-grade cervical abnormalities is common in younger patients (Kurman et al., 2011), which is in agreement with these studies once the median age of HIV+ and HIV- women was below 35 years old (Entiauspe et al., 2010; Oliveira et al., 2010; Andrade et al., 2011; Melgaco et al., 2011; Teixeira et al., 2012).

As expected, studies performed to detection HPV at the molecular level together with cervical cytology and/ or histopathology showed an association of HR-HPV with cervical abnormalities (Mattos et al., 2011), mostly HSIL (Melgaco et al., 2011) or CIN II/III and SCC (Andrade et al., 2011).

\section{Prevalence of HPV and Cervical Abnormalities in HIV+ Brazilian Pregnant Women}

During pregnancy, there is a decrease in immunity, especially in the genitals. Hormonal and immunosuppressive factors which are necessary for the maintenance of a fetus, could predispose women to the 
development of HPV-induced lesions. Furthermore, the vaginal microbiota becomes imbalanced, favoring the development of infectious agents (Brandao et al., 2010). Some articles assessing the prevalence of HPV in HIV+ pregnant women were performed in the Southern and Southeast regions of Brazil.

In the Southern region, Tornatore et al. (2012) conducted a cross-sectional study which evaluated the presence of cervical abnormalities in $\mathrm{HIV}+$ pregnant women. A high prevalence of cytological abnormalities was found $(40.8 \%)$, and $52.9 \%$ of these patients showed HSIL. Another study in the same region evaluated the co-infection of HIV/HPV in pregnant and non-pregnant woman. The frequency of HPV infections among pregnant $\mathrm{HIV}+(29.2 \%)$ or HIV- $(25.0 \%)$ was higher compared with the non-pregnant HIV+ $(10.0 \%)$ or HIV- $(13.6 \%)$ women. The authors suggest that this fact may be due to the immunomodulatory feature during the period of pregnancy, causing an increase in cases of HPV. The most prevalent HR-HPV genotypes detected were HPV -16 , $-58,-18$ and -33 , and LR-HPV was HPV-6. The results of cytological findings were predominantly NILM $(95.8 \%)$ with LSIL and HSIL in $4.2 \%$ of patients (Oliveira et al., 2013).

In the Southeast region, Meyrelles et al. (2013) showed HPV-DNA in $84.3 \%$ of HIV+ pregnant women, with 28 different genotypes. The HR-HPV genotypes were detected in the majority of cases $(79.8 \%$ versus $20.2 \%$ of LR-HPV), and HPV co-infections occurred in $16.3 \%$ of cases. HPV-16 was the most frequent, followed by other HR-HPV genotypes (-58, -35 and -53) (Table 1). Cytological abnormalities were found in $31.4 \%$ of these women, in which LSIL was the majority (70.0\%). There was a significant association between HPV infection and CD4+ cell counts less than 350 cells $/ \mathrm{mm}^{3}$, highlighting the immune function in viral infection resistance and cervical abnormalities. Another study evaluated the elimination of HPV in HIV+ and HIV- women during pregnancy and postpartum. After initial detection and genotyping of HPV, women were followed in successive visits during pregnancy and postpartum. A higher HPV elimination in postpartum was observed compared to pregnancy. However, HIV+ women took a longer time to eliminate HPV compared with those not infected with HIV, strengthening the notion that HIV infection could retard HPV elimination (Vaz et al., 2011). The most prevalent HPV genotypes were LR-HPV, including HPV-6 and -11, followed by HR-HPV $-18,-16$ and -31 (Table 1). Greater elimination of HPV was observed in women infected by LR-HPV compared to HR-HPV, but this difference was not significant (Jalil et al., 2013).

\section{Conclusions}

Several previous studies showed the relationship between HPV infection and an increased risk of SCC among HIV+ women around the world, predominantly in LMICs such as Brazil. In this context, this review summarized some studies that evaluated the molecular prevalence of HPV and cervical abnormalities by cytology and/or histology in different regions of Brazil.
The majority of studies found between 2010 and 2014 were conducted in the Southern and Southeast regions of Brazil and showed that HPV infection had a high prevalence in HIV+ women. However, in the majority of studies, there was a low presence of cervical abnormalities, and predominantly low-grade cervical abnormalities were found by cytological and histological analysis. It could be that these occurred because the majority of studies were realized in developed regions of Brazil where HIV infection is well controlled by HAART use. Nevertheless, some studies that compared HIV+ and HIV- women showed the greatest prevalence of cervical abnormalities in HIV+ women. Furthermore, to verify the genotypes most prevalent in these populations, it is important to evaluate the effectiveness of vaccine programs. In this review, HR-HPV was more frequently found and HPV16 was the most common genotype, but a great variety of unusual genotypes were observed. Still, the prevalence of HPV genotype co-infections was high. Brazil is considered a LMIC and is a country with great disparities around different regions, so this study could serve as model of LMICs and low-resource settings. However, further studies are needed, mainly in low-resource settings regions of Brazil for a more comprehensive assessment.

\section{References}

Adler DA (2010). The impact of HAART on HPV-related cervical disease. Curr HIV Res, 8, 493-7.

Andrade ACVd, Luz PM, Velasque L, et al (2011). Factors associated with colposcopy-histopathology confirmed cervical intraepithelial neoplasia among HIV-infected women from Rio De Janeiro, Brazil. PloS one, 6, 18297.

Araujo ACL, Carvalho NO, Teixeira NC, et al (2012). Incidence of cervical intraepithelial neoplasia in a cohort of HIVinfected women. Int J Gynecol Obstet, 117, 211-6.

Beachler DC, Abraham AG, Silverberg MJ, et al (2014). Incidence and risk factors of HPV-related and HPV-unrelated head and neck squamous cell carcinoma in HIV-infected individuals. Oral Oncol, 50, 1169-76.

Blossom DB, Beigi RH, Farrell JJ, et al (2007). Human papillomavirus genotypes associated with cervical cytologic abnormalities and HIV infection in Ugandan women. J Med Virol, 79, 758-65.

Boletim Epidemiologico - Aids e DST (2014). Ministerio da saude - secretaria de vigilancia em saude - departamento de DST, aids e hepatites virais. Brasilia: Brasil.

Brandao VCRAB, Lacerda RL, Ximenes RAA, et al (2010). Frequencia de Papilomavirus humano (HPV) e Chlamydia trachomatis em gestantes. Epidemiol Serv Saude, 19, 43-50.

Correa CM, Teixeira NCP, Araujo ACLd, et al (2011). Prevalence and multiplicity of HPV in HIV women in Minas Gerais, Brazil. Rev Assoc Med Bras, 57, 425-30.

De Sanjose S, Quint WGV, Alemany L, et al (2010). Human papillomavirus genotype attribution in invasive cervical cancer: a retrospective cross-sectional worldwide study. Lancet Oncol, 11, 1048-56.

Denny LA, Franceschi S, de Sanjose S, et al (2012). Human Papillomavirus, Human Immunodeficiency Virus and Immunosuppression. Vaccine, 5, 168-74.

Entiauspe LG, Teixeira LO, Mendoza-Sassi RA, et al (2010). Papilomavirus humano: prevalencia e genotipos encontrados em mulheres HIV positivas e negativas, em um centro de referencia no extremo Sul do Brasil. Rev Soc Bras Med 
HPV Infection and Cervical Abnormalities in HIV Positive Women in Different Regions of Brazil, a Middle-Income Country

Trop, 43, 260-3.

Fedrizzi EN, Laureano JK, Schlup C, et al (2011). Infeccao pelo papilomavirus humano (HPV) em mulheres HIV-positivo de Florianopolis, Santa Catarina. DST J Bras Doencas Sex Transm, 23.

Felix G, Ceolim MF (2012). O perfil da mulher portadora de HIV/AIDS e sua adesao a terapeutica antirretroviral. Rev Esc Enferm USP, 46, 884-91.

Ferlay J, Shin HR, Bray F, et al (2010). Estimates of worldwide burden of cancer in 2008: GLOBOCAN 2008. Int J Cancer, 127, 2893-917.

Firnhaber C, Evans D, Friedman-Khalili R, et al (2011). Seroprevalence of HPV vaccine types 6, 11, 16 and 18 in HIV-infected women from South Africa, Brazil and Botswana. J Clin Virol, 52, 265-8.

Instituto Nacional de Cancer - INCA (2014). Incidencia de Cancer no Brasil, estimativa 2014. Rio de Janeiro, RJ, Brasil.

Instituto Nacional de Cancer - INCA (2014). Estimativas: Neoplasia maligna do colo do utero.

International Agency for Research on Cancer (IARC) - World Health Organization (2012). Cervical Cancer: Estimated Incidence, Mortality and Prevalence Worldwide in 2012.

International Agency for Research on Cancer (IARC) - World Health Organization (2011). Monographs on the evaluation of carcinogenic risk to humans. Volume 100B: A review of human carcinogens: biological agents. Lyon - France.

Jalil EM, Bastos FI, Melli PP, et al (2013). HPV clearance in postpartum period of HIV-positive and negative women: a prospective follow-up study. BMC Infectious Diseases, 13,564 .

Joura EA, Giuliano AR, Iversen OE, et al (2015). A 9-Valent HPV vaccine against infection and intraepithelial neoplasia in women. $N$ Engl J Med, 372, 711-23.

Koh WJ, Greer BE, Abu-Rustum NR, et al (2015). Cervical cancer, version 2.2015. JNCCN, 13, 395-404.

Kurman RJ, Ellenson LH, Ronnett BM (2011). Blaustein's Pathology of the female genital tract, $6^{\text {th }}$ edn. New York: Springer Verlag, 1246.

Lima MDM, Braz-Silva PH, Pereira SM, et al (2014). Oral and cervical HPV infection in HIV-positive and HIV-negative women attending a sexual health clinic in Sao Paulo, Brazil. Int J Gynecol Obstet, 126, 33-6.

Luque AE, Hitti J, Mwachari C, et al (2010). Prevalence of human Papillomavirus genotypes in HIV-1-infected women in Seattle, USA and Nairobi, Kenya: results from the Women's HIV Interdisciplinary Network (WHIN). J Infect Dis, 14, 810-804.

Marur S, D'Souza G, Westra W, et al (2010). HPV-associated head and neck cancer: a virus related cancer epidemic. Lancet Oncol, 11, 781-9.

Mattos ATd, Freitas LBd, Lima BMC, et al (2011). Diversity and uncommon HPV types in HIV seropositive and seronegative women attending an STI clinic. Braz J Microbiol, 42, 786-93.

McKenzie ND, Kobetz EN, Hnatysyn J, et al (2010). Women with HIV are more commonly infected with non-16 and -18 high-risk HPV types. Gynecol Oncol, 116, 572-7.

Melgaco FG, Rosa MLG, Augusto EF, et al (2011). Human papillomavirus genotypes distribution in cervical samples from women living with human immunodeficiency virus. Arch Gynecol Obstet, 283, 809-17.

Meyrelles ARI, Siqueira JD, Hofer CB, et al (2013). HIV/ HPV co-infection during pregnancy in southeastern Brazil: Prevalence, HPV types, cytological abnormalities and risk factors. Gynecol Oncol, 128, 107-12.

Oliveira PM, Oliveira RPC, Travessa IEM, et al (2010). Prevalence and risk factors for cervical intraepithelial neoplasia in HIV-infected women in Salvador, Bahia, Brazil.
Sao Paulo Med J, 128, 197-201.

Ortiz AP, Perez-Irizarry J, Soto-Salgado M, et al (2014). Human papillomavirus-related cancers among people living with AIDS in Puerto Rico. Prev Chronic Dis, 11, 80.

Paim J, Travassos C, Almeida C, et al (2011). The Brazilian health system: history, advances, and challenges. Lancet, 377, 1778-97.

Paulo M, Borges AB, Duarte G, et al (2007). The environmental cofactors in carcinogenesis in high risk HPV/HIV-positive women. Braz J Infect Dis, 11, 189-95.

Piketty C, Selinger-Leneman H, Bouvier A-M, et al (2012). Incidence of HIV-related anal cancer remains increased despite long-term combined antiretroviral treatment: results from the French hospital database on HIV. Clin Oncol, 30, 4360-6.

Portal Brasil (2015). Mortalidade de AIDS cai $13 \%$ nos ultimos 10 anos no Brasil.

Portal Brasil (2015). Relatorio contabiliza casos de HIV/AIDS na America Latina.

Requejo HIZ (2006). Worldwide molecular epidemiology of HIV. Rev Saude Publica, 40, 331-45.

Rocha-Brischiliari SC, Gimenes F, de Abreu ALP, et al (2014). Risk factors for cervical HPV infection and genotypes distribution in HIV-infected South Brazilian women. Infec Agents Cancer, 9, 1-6.

Rosa MI, Fachel JM, Rosa DD, et al (2008). Persistence and clearance of human papillomavirus infection: a prospective cohort study. Am J Obstet Gynecol, 199, 617.

Santos NJS, Barbosa RM, Pinho AA, et al (2009). Contextos de vulnerabilidade para o HIV entre mulheres brasileiras. $\mathrm{Cad}$ Saude Publica, 25, 321-33.

Shrestha S, Sudenga SL, Smith JS, et al (2010). The impact of highly active antiretroviral therapy on prevalence and incidence of cervical human papillomavirus infections in HIV-positive adolescents. BMC Infect Dis, 10, 295.

Smith-McCune KK, Shiboski S, Chirenje MZ, et al (2010). Type-specific cervico-vaginal human papillomavirus infection increases risk of HIV acquisition independent of other sexually transmitted infections. PloS one, 5, 10094.

Solomon D, Nayar R (2005). Sistema Bethesda para citopatologia cervicovaginal: definicoes, criterios e notas explicativas: Revinter.

Spangler JM, Munger K (2010). The human Papillomavirus type 16 E6 oncoprotein activates mTORC1 signaling and increases protein synthesis. J Virol, 84, 9398-407.

Stier E (2009). Human papillomavirus related diseases in HIVinfected individuals. Curr Opin Oncol, 20, 541-6.

Sudenga SL, Wiener HW, King CC, et al (2014). Dense genotyping of immune-related loci identifies variants associated with clearance of HPV among HIV-positive women in the HIV epidemiology research study (HERS). Plos One, 9, 99109.

Teixeira NCP, Araujo ACL, Correa CM, et al (2012). Prevalence and risk factors for cervical intraepithelial neoplasia among HIV-infected women. Braz J Infect Dis, 16, 164-9.

Tornatore M, Goncalves CV, Bianchi MS, et al (2012). Coinfections associated with human immunodeficiency virus type 1 in pregnant women from southern brazil: high rate of intraepithelial cervical lesions. Mem Inst Oswaldo Cruz, 107, 205-10.

Vaz LP, Saddi VA, Amaral WNd, et al (2011). Epidemiologia da infeccao pelo HPV em mulheres infectadas pelo HIV. Femina, 39, 35-40. 